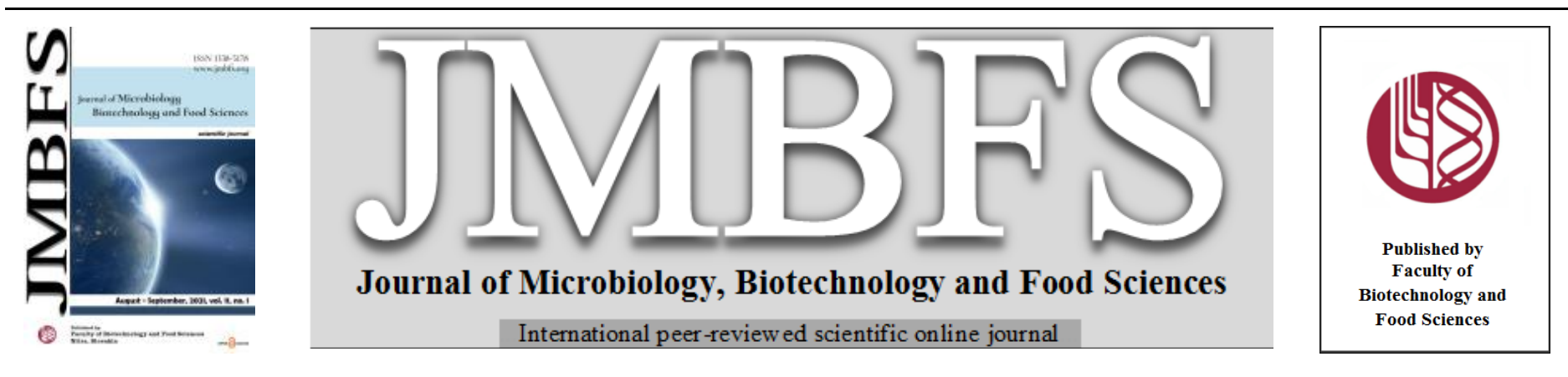

\title{
STRUCTURAL ANALYSIS OF PLASMID-MEDIATED VEROTOXIN GENE PRODUCING NON-O157 ESCHERICHIA COLI USING MOLECULAR DYNAMIC SIMULATIONS
}

\section{Md Fazlul Karim Khan ${ }^{1}$, Shah Samiur Rashid * ${ }^{1}$, Aizi Nor Mazila Ramli ${ }^{1}$, Muhammad Nomani Kabir ${ }^{2}$, and Mohammad Nazmul Hasan Maziz ${ }^{3}$}

\author{
$\operatorname{Address(es):~}$ \\ ${ }^{1}$ Faculty of Industrial Sciences \& Technology, Universiti Malaysia Pahang, Gambang, 26300 Pahang, Malaysia. \\ ${ }^{2}$ Faculty of Computing, Universiti Malaysia Pahang, Gambang, 26300 Pahang, Malaysia. \\ ${ }^{3}$ Graduate School of Medicine, Perdana University, Wisma Chase Perdana, Changkat Semantan, Damansara Heights, 50490 Kuala Lumpur, Malaysia.
}

*Corresponding author: samiur@ump.edu.my, stagnant_obit@yahoo.com

https://doi.org/10.15414/jmbfs.4142

\section{ARTICLE INFO}

Received 28. 12. 2020

Revised 25. 2. 2021

Accepted 3. 3. 2021

Published 1. 8. 2021

Regular article

OPEN $\partial_{\text {ACCESS }}$

\begin{abstract}
Plasmid-mediated Non-O157 VTEC is a pathogenic E. coli serotype, are responsible for many life-threatening diseases such as diarrhoea. The thermostable crystal structure has been widely sought after for industry and therapeutic applications through the structural analysis. The National Center for Biotechnology Information (NCBI) Genbank Database has been sourced to obtain plasmidmediated Verotoxin genes producing non-O157 MN 696158 (Vtx1-1) and MN688720 (Vtx2) sequences. The tertiary structure of MN696158 (Vtx1-1) and MN688720 (Vtx2) was generated by operating MODELLER. The result exposed multiple templates during modelling processes have improved the local stereochemical quality of the produced models. The structural analysis also disclosed the similarities and differences between the models (Vtx1-1 and Vtx2). Furthermore, the thermal stability profile of plasmid-mediated nonO157 VTEC were studied. The molecular dynamics simulations of plasmid-mediated non-O157 VTEC structures (Vtx1-1 and Vtx2) illustrated the interactions between amino acids. On the other hand, Vtx1-1 and Vtx2 showed noticeable differences in their relative conformational flexibility and stability at elevated temperature. However, it is expected that the information of the thermal stable of plasmid-mediated non-O157 VTEC models can be used for potential vaccine candidate through protein engineering in future.
\end{abstract}

Keywords: Verotoxin gene, GROMACS, Molecular dynamic simulations, Non-O157 E. coli

\section{INTRODUCTION}

Non-O157 Verotoxin producing E. coli (VTEC) is gradually recognised as a critical enteric foodborne pathogen which associates with life threatening complications (Colello et al., 2016; Khan et al., 2020). The production of verotoxin related virulence properties causes mild diarrhea, hemorrhagic colitis (HC), and fatal hemolytic uremic syndrome (HUS) across the worldwide. Generally, E. coli O157: H7 serotypes associated with foodborne illness and non-O157 serotypes have been accused of gastroenteritis and HUS outbreaks (Public Health England, 2018). Furthermore, VTEC has become a major public health issue in combination with serious food-borne disease and diseases (Mei et al., 2015; Khan et al., 2020).

In eukaryotic cells, Vtx is one of the virulent factors which produces one or more toxin which. inhibits protein synthesis. (Cheung \& Trachtman, 2014). These are known as Shiga toxin-producing E. coli (STEC) or Verotoxin producing E. coli (VTEC) (Nazmul et al., 2012; Kaper \& O'Brien, 2014). The Vtx genes (Vtx1 and Vtx2) have the same structure and variation of the Vtx 1 and Vtx 2 sequences and variants has been defined (Hazards, 2013; khan et al., 2020). Moreover, Vtx is the usual member of the bacteria of type 2 ribosome-inactivating protéins (RIPs) (Zhu et al., 2018). In laboratory conditions, the determination of the protein structure requires time and energy and is not an economic process. (HaiYou et al., 2016). In knowledge-based material, structural analysis of proteins is crucial while 3D (3-D) arrangement of amino acid atoms could provide the best solution for homology or comparative modelling. The simulation of molecular dynamics can also improve structure prediction with the lowest error and loss of data (Geng et al., 2019). X-ray crystallography and NMR is typically the most effective approach to solve protein structures across various steps. (Su $\boldsymbol{e t}$ al. 2015). Protein structures of the same molecule have four distinct stages, referring to the prediction of secondary protein structure, modelling homology, molecular docking and molecular dynamic simulations. (Muhammed \& Aki-Yalcin, 2019).

Pathogenic associations with host cells also affect infectious diseases in practise (Fazlul et al., 2011; Fazlul et al., 2018). Thus, we attempt to generate multi- templates of plasmid-mediated verotoxin models. The truth is that a single template cannot cover the entire verotoxin sequence and thus multiple templates should be implemented to cover the entire sequence of the modelled verotoxin. In addition, a multiple templates combination may also cover one template's weakness by another template (Chakravarty et al., 2008). The models created allows the analysis of interactions in plasmid-mediated non-O157 E. coli verotoxin gene sequences. The predicted verotoxin structures were also simulated to show conformation changes in the height temperature. This provides explicit structural information to the verotoxin gene that is essential for better enzyme control.

\section{METHODS AND MATERIALS}

\section{Model development}

The plasmid mediated verotoxin producing amino acid sequences of MN696158 (Vtx1-1) and MN688720 (Vtx2) were obtained from NCBI Genbank and BLAST for finding acceptable models against the PDB database. Single and multiple models that have been chosen for Modelling was based on the coverage length, identity of the sequence and differences between the target and the template. Plasmid mediated verotoxin gene via MODELLER version 9.20 (Heo \& Feig, 2018), models were produced. A hundred suitable models based on the lowest discrete optimised protein energy (DOPE) scores were chosen for the best one. The appropriate model was then subjected to a molecular dynamics simulation model refinement process.

\section{Refinement process}

The refinement approach was implemented with some alterations (Heo \& Feig, 2018). First of all, the local stereochemistry of the chosen component models of verotoxin were refined using locPREFMD server before simulation of molecular dynamics using 5.1.4 GROMACS (Heo \& Feig, 2018). The simulation was done by in a simple cubic box with a minimum of $10 \AA$ from the edge of the box with 
a force field of CHARMM36m (Huang et al., 2017). With TIP3P water molecules, the mechanism was solved, and a sufficient number of sodium ions was neutralized. The ensemble was after that, energy reduced by 5000 steps of the steepest descent algorithm and balanced at NVT phase to $298 \mathrm{~K}$ (constant number of particles, volume and temperature) and 1 bar pressure at 1 bar pressure NPT process for $100 \mathrm{ps}$, respectively (constant number of particles, pressure and temperature). Ultimately, the simulation was performed for $50 \mathrm{~ns}$ at $298 \mathrm{~K}$ and 1 bar pressure. To constrain the bond, LINear Constraint Solver (LINCS) was used, whereas the electrostatic interactions were assessed by both Coulomb and van der Walls interactions, the particle mesh Ewald process (PME) with a $12 \AA$ cut-off. The integration time stage was $2 \mathrm{fs}$, and every 1 ps during the simulation, a snapshot of the structures was taken. The stability of the trajectory was assessed using the GROMACS functionality by root-mean-square deviation (RMSD) and radius of gyration $(\mathrm{Rg})$. For the final round of local stereochemistry refinement, the stabilized structure was extracted and introduced to locPREFMD.

\section{Model evaluations}

The stereochemical content of the VTX models was determined and evaluated by Verify 3D (Chakkyarath \& Natarajan, 2019), ERRAT (Soumiya et al., 2019) and PROCHECK (Chakkyarath \& Natarajan, 2019) via structure analysis and verification server version 5.0 (SAVES 5.0). The energy level of the VTX models was calculated using Swiss-PdbViewer (Amir et al., 2019). The molecular visualization of the protein-protein interactions was demonstrated in the PyMOL 2.2.2 edition (Faure et al., 2019).

\section{Thermal study for protein deterioration}

Protein deterioration analysis plays an essential role in the process of therma stability determination with exponential growth or decay with time. The Vtx sample was prepared using proteolytic activity assays as described by Duanisassaf (Duanis-Assaf et al., 2020) to determine the optimum temperature and allowed to hydrolyse casein for 10 minutes at $20{ }^{\circ} \mathrm{C}, 30^{\circ} \mathrm{C}, 40{ }^{\circ} \mathrm{C}, 50{ }^{\circ} \mathrm{C}$ and 60 ${ }^{\circ} \mathrm{C}$. The reaction was terminated by trichloroacetic acid (TCA) (concentration of $110 \mathrm{mM}$ ), and the reaction mixture was centrifuged, and the supernatant was mixed with $\mathrm{Na}_{2} \mathrm{CO}_{3}$ (concentration of $500 \mathrm{mM}$ ) while $\mathrm{F}-\mathrm{C}$ phenol reagent (concentration of $0.5 \mathrm{M}$ ) for colour development. In the preparation of (TCA) and
Folin and Ciocalteu's (F-C) phenol, both the reagents were diluted to a final concentration of $110 \mathrm{mM}$ and $0.5 \mathrm{M}$, respectively from their stock solution. Sodium carbonate $\left(\mathrm{Na}_{2} \mathrm{CO}_{3}\right)$ buffer was prepared by adding $53 \mathrm{~g}$ of anhydrous $\mathrm{Na}_{2} \mathrm{CO}_{3}$ in $1 \mathrm{~L}$ of distilled water to a final concentration of $500 \mathrm{mM}$. After that, the crude samples were incubated at five elevated temperatures of $20^{\circ} \mathrm{C}, 30^{\circ} \mathrm{C}$, $40{ }^{\circ} \mathrm{C}, 50{ }^{\circ} \mathrm{C}$, and $60{ }^{\circ} \mathrm{C}$ without substrate for 1 hour. Similarly, the hydrolysis was conducted at $37^{\circ} \mathrm{C}$, as described above. A plot of Vtx activity against elevated temperatures was generated.

\section{Thermal dynamic behaviours}

The refined verotoxin models were set to the molecular dynamic simulation to examine dynamics and conformation variations at the specified temperature. Three separate systems have been developed for each verotoxin model, dissolved with TIP3P water molecules and neutralized by a sufficient number of sodium ions. After that, energy was minimized by 5000 steps of the steepest descent algorithm and balanced at $300 \mathrm{~K}, 313 \mathrm{~K}$ and $323 \mathrm{~K}$, respectively, through NVT and NPT. Consequently, the simulation was done for $100 \mathrm{~ns}$. LINCS was used to constrain bond length, while electrostatic interactions were assessed by SMEs with a $12 \AA$ cut-off for both Coulomb and van der Walls correlations. The integration time stage was $2 \mathrm{fs}$ and the structure snapshot was reported every $1 \mathrm{ps}$ during the simulation. Besides, dynamic behavior and conformational changes of VTX models were investigated by RMSD analysis, root-mean-square fluctuation (RMSF), Rg, solvent-accessible surface area (SASA) and hydrogen bond number.

\section{RESULTS AND DISCUSSION}

\section{Comparative modelling and model refinement}

The similarities and differences among the Vtx1-1and Vtx2 were determined while comparison studies disclosed important structural information of $\mathrm{Vtx}$ protein. The isolated Vtx gene sequences were BLAST against the PDB database for an appropriate Vtx protein model. The protein BLAST result revealed that Vtx1-1 are vastly identical to $1 \mathrm{R} 4 \mathrm{Q} \_\mathrm{A}$ with percent identity of $95.11 \%$, while 96.21\% identity to 4M1U_A was observed in Vtx2 (Table 1 and Table 2).

Table 1 Templates of protein revealed the maximum similarity with Vtx1-1 sequences based on various parameters

\begin{tabular}{llccccc}
\hline \multirow{2}{*}{ Template } & PDB report & Query analysis (\%) & E-value & $\begin{array}{c}\text { Identity } \\
(\boldsymbol{\%})\end{array}$ & $\begin{array}{l}\text { Gaps } \\
(\boldsymbol{\%})\end{array}$ \\
\hline 4M1U_A & & & & Score & 10 \\
1R4P_A & Chain A, Shiga toxin & 83 & $2 \mathrm{e}-77$ & 55.61 & 209 & 10 \\
1DM0_A & Chain A, Shiga toxin & 83 & $2 \mathrm{e}-67$ & 57.61 & 209 \\
1R4Q_A & Chain A, Shiga toxin & 88 & $5 \mathrm{e}-118$ & 95.05 & 10 \\
4P2C_A & Chain A, Shiga Toxin & 88 & $4 \mathrm{e}-118$ & 95.11 & 337 \\
\hline
\end{tabular}

Table 2 Templates of protein revealed the maximum similarity with Vtx2 sequences based on various parameters

\begin{tabular}{lllllll}
\hline Template & PDB report & $\begin{array}{l}\text { Query } \\
\text { analysis (\%) }\end{array}$ & E-value & $\begin{array}{l}\text { Identity } \\
(\boldsymbol{\%})\end{array}$ & $\begin{array}{c}\text { Gaps } \\
(\boldsymbol{\%})\end{array}$ & $\begin{array}{c}\text { Score } \\
\end{array}$ \\
\hline 4M1U_A & Chain A, Shiga toxin & 100 & $7 \mathrm{e}-147$ & 96.21 & 3 & 400 \\
1R4P_A & Chain A, Shiga toxin & 100 & $7 \mathrm{e}-147$ & 96.21 & 3 & 400 \\
4P2C_A & Chain A, Shiga Toxin & 100 & $9 \mathrm{e}-135$ & 88.63 & 3 & 369 \\
1R4Q_A & Chain A, Shiga toxin & 98 & $9 \mathrm{e}-90$ & 61.06 & 4 & 255 \\
1DMO_A & Chain A, Shiga toxin & 11 & 1.6 & 26.09 & 0 & 16.9 \\
\hline
\end{tabular}

However, the query coverage of Vtx1-1 by 1R4Q_A was only $88 \%$, although Vtx2 exhibited the most extended query coverage of $100 \%$. Furthermore, the least E-value and gap with 4M1U_A, 1R4Q_A, 4P2C_A, 1DM0_A, and 1R4P_A was considered to finalize based on the recommendation by several studies (Kerfeld \& Scott, 2011; Frith, 2019) for an appropriate alignment amongst the sequences.

Primarily, 1R4Q_A has appeared as the best template due to the most extended coverage $(88 \%)$ and sequence identity of $95.11 \%$ for Vtx1-1 protein model Besides, 4M1U_A has the highest coverage $(100 \%)$ with the sequence identity of $96.21 \%$ and was selected for Vtx2. According to a recent study, protein modelled with a template of 30-50\% identity will not exceed $4 \AA$ RMSD from its native structure (Monzon et al., 2017). Furthermore, the gap between gene sequences has to very low (1-2 \%) to evade misalignment amongst the target and template sequence, which may mislead the structured protein (Dorn et al., 2014). The protein sequences of Vtx1, Vtx1-1, and Vtx2 was aligned with the available protein data structure in NCBI databases associated with the PDB database. The most compatible protein data was selected based on the various parameters to build up the perfect models.

In this study, a set of 100 templates for each Vtx sequences was generated to provide a pool of perfect results (Sefidbakht $\boldsymbol{e t}$ al., 2017). The excellent model was distinguished from the bad models using the MODELLER in-built assessment method based on DOPE score. DOPE is a potential statistical assessment that corresponds to non-interacting atoms in a homogeneous sphere with the radius dependent on a native sample structure (Jing \& Dong, 2017). A lower DOPE score indicates the structure has a better packing of the atoms and is more accurate at its native conformation (Cloete et al., 2018). These scoring methods are precise sufficiently to select the most authentic model among the generated models using the MODELLER (Webb \& Sali, 2017).

The stereochemical consistency of the desired models must be carried out for further assessment. These selected models were investigated using the SAVES 5.0 server using various evaluation programs such as Verify $3 \mathrm{D}$, which calculates the number of residues in an atomic model consistent with its amino acid sequence of $80 \%$ (Tran et al., 2015). Meanwhile, ERRAT analysed the statistics of non-bonded interactions amongst various atom types (Wei et al., 2017); and PROCHECK assessed the protein stereochemical quality of a protein models in favoured, allowed and outlier regions (Elengoe et al., 2014). These scoring methods are often satisfactorily adequate to select the most accurate generated models (Haddad et al., 2020).

Among the accurate generated models, 4M1U_A for Vtx1-1 protein was selected based on the scoring methods shown in Table 3. However, the Vtx1-1 protein structure passed the Verify 3D test with a score of $93.82 \%$, ERRAT (97.76) and PROCHECK (93.4\%). Meanwhile, 4P2C_A was selected template for Vtx2 protein with a Verify 3D score of $94.95 \%$, ERRAT (87.28) and PROCHECK $(87.6 \%)$ have satisfactory phi and psi dihedral angle allocations of amino acid residues in the modelled structures. Both Vtx1-1 (4M1U_A) and Vtx2 (4P2C_A) revealed an excellent quality of predicted protein model based on the evaluation tool ProQ server (Sajib et al., 2020). 
Table 3 Models assessment using Verify 3D, ERRAT and PROCHECK

\begin{tabular}{|c|c|c|c|c|}
\hline Model & Template & $\begin{array}{l}\text { Verify 3D } \\
(\%)\end{array}$ & ERRAT & PROCEHCK (\%) \\
\hline \multirow[t]{5}{*}{$\begin{array}{l}\text { Vtx1- } \\
1\end{array}$} & 4M1U_A & 93.82 & 97.76 & $\begin{array}{l}\text { Favoured region:93.4 } \\
\text { Allowed region: } 6.6 \\
\text { Outlier region:0.0 }\end{array}$ \\
\hline & 1R4P_A & 93.98 & 95.29 & $\begin{array}{l}\text { Favoured region:92.6 } \\
\text { Allowed region:7.4 } \\
\text { Outlier region:0.0 }\end{array}$ \\
\hline & 1DM0_A & 75.49 & 100 & $\begin{array}{l}\text { Favoured region: } 85.3 \\
\text { Allowed region: } 14.9 \\
\text { Outlier region:0.0 }\end{array}$ \\
\hline & 1R4Q_A & 87.29 & 91.92 & $\begin{array}{l}\text { Favoured region:85.9 } \\
\text { Allowed region: } 14.0 \\
\text { Outlier region:0.1 }\end{array}$ \\
\hline & 4P2C_A & 94.95 & 87.28 & $\begin{array}{l}\text { Favoured region: } 87.6 \\
\text { Allowed region: } 11.7 \\
\text { Outlier region:0.8 }\end{array}$ \\
\hline \multirow[t]{5}{*}{ Vtx2 } & 4M1U_A & 87.29 & 91.92 & $\begin{array}{l}\text { Favoured region:85.9 } \\
\text { Allowed region: } 14.0 \text {. } \\
\text { Outlier region:0.1 }\end{array}$ \\
\hline & 1R4P_A & 92.15 & 83.18 & $\begin{array}{l}\text { Favoured region:92.6 } \\
\text { Allowed region:7.4 } \\
\text { Outlier region:0.0 }\end{array}$ \\
\hline & 4P2C_A & 94.95 & 87.28 & $\begin{array}{l}\text { Favoured region:87.6 } \\
\text { Allowed region: } 11.7 \\
\text { Outlier region:0.8 }\end{array}$ \\
\hline & 1R4Q_A & 87.29 & 91.92 & $\begin{array}{l}\text { Favoured region: } 85.9 \\
\text { Allowed region: } 13.4 \\
\text { Outlier region:0.6 }\end{array}$ \\
\hline & 1DM0_A & 75.49 & 100 & $\begin{array}{l}\text { Favoured region: } 85.3 \\
\text { Allowed region: } 14.2 \\
\text { Outlier region: } 0.6\end{array}$ \\
\hline
\end{tabular}

Overall, the correctness of the Vtx1-1 protein structure globally was measured by LG score of 6.716 with a MaxSub score of 0.541 to assess the quality of the protein structure while Vtx2 obtained LG score of 5.794 and a MaxSub score of 0.525 . Therefore, the final selected models are Vtx1-1 (4M1U_A) and Vtx2 (4P2C_A) based on their overall stability in Verify 3D, ERRAT, and PROCHECK, and other assessment tools. These final models were successively used in further analysis.

\section{Model refinement}

The initial protein structure model may not always be accurate (Ganugapati \& Akash, 2017), and this comparative model has to go for further validation for better accuracy. In this study, the Vtx structure was improved using multiple similar known templates. The structure may still contain errors due to differences (insertions and gaps) in amino acids amongst target and templates during the absences of biomolecules (proteins, nucleic acid and ligands) interactions (Feig, 2017). In comparative modelling, the primary protein structure has to refine to achieve enhanced accuracy (Heo \& Feig, 2018). In the current study, the Vtx structures were refined through molecular dynamics simulation. Molecular dynamics refine the structure of the proteins and shapes a group of conformities to their native state. (Raval et al., 2012). Hence, the stability of the Vtx structure was estimated as a function of simulation time. The value of RMSD for Vtx1-1 was consistently deviated at $\sim 2.5 \AA$ after $5 \mathrm{~ns}$ till $40 \mathrm{~ns}$ while fluctuated between $2 \AA$ and $2.5 \AA$ at $40 \mathrm{~ns}$ to $50 \mathrm{~ns}$. Consequently, Vtx2 reached a plateau state at around $2.0 \AA$ after $10 \mathrm{~ns}$ and consistently deviated between $2 \AA-2.5 \AA$ until the end of the simulation. Overall, RMSD values of Vtx1-1 and Vtx2 fluctuated and deviated between 2.0-2.5 $\AA$ after 5 ns (Figure 1(a)).

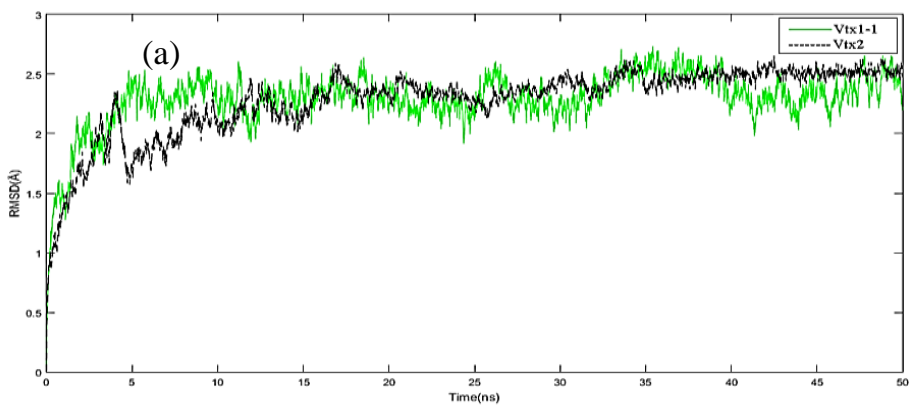

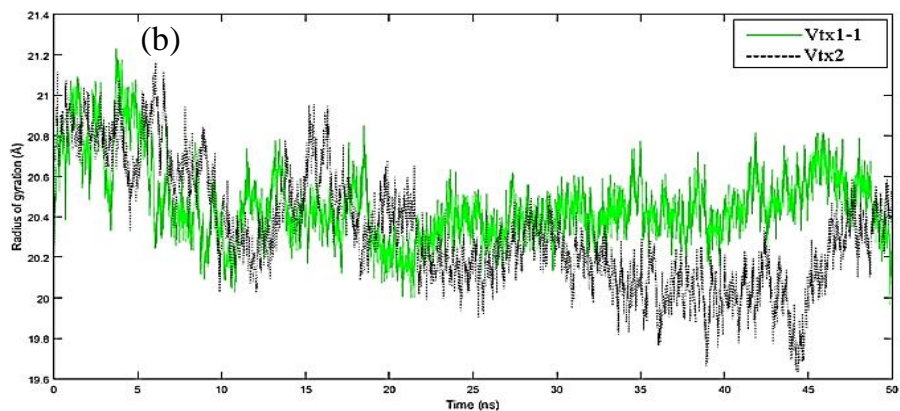

Figure 1 RMSD (a) indicate the overall stability of Vtx1-1, and Vtx2 during the simulation. Radius of gyration (b) representing the overall dimension of Vtx1-1 and $\mathrm{Vtx} 2$ was as a function of time

The simulation time is sufficient based on the RMSD value to facilitate the Vtx structure to reach a stabilised state. Furthermore, the radius of gyration was evaluated for the stability of the Vtx models. The compactness of a protein structure was determined through the radius of gyration (Lobanov et al., 2008). Gyration values revealed that the compactness of Vtx1-1 (20. $\AA-21.2 \AA)$ and Vtx2 (19.6 $\AA-21.2 \AA)$ was maintained without substantial drift, signifying the predicted Vtx structure throughout the simulation (Figure 1 (b)).

The quality of the initial Vtx models structure was refined by MODELLER prior to the locPREFMD refinement process to get the most suitable model for further analysis. Verify 3D showed that the percentages of amino acid with correct 3D fold (Vtx1-1: $87.97 \%$; Vtx2: $80.00 \%$ ). Besides that, ERRAT analysis also indicted on nonbonded interactions within the Vtx model (Vtx1-1: $91.59 \%$; and Vtx2: $82.75 \%$ ). The PROCHECK Ramachandran plot indicated that $100 \%$ and $99.3 \%$ of the Vtx1-1 and Vtx2 amino acid residues are located in preferred, approved areas, respectively.

Table 4 Evaluations between the initial models and refined models

\begin{tabular}{lllll}
\hline Model & $\begin{array}{l}\text { Energy } \\
(\mathbf{k J} / \mathbf{m o l})\end{array}$ & $\begin{array}{l}\text { Verify } \\
(\boldsymbol{\%})\end{array}$ & $\begin{array}{l}\text { 3D } \\
(\boldsymbol{\%})\end{array}$ & PROCEHCK (\%) \\
\hline Vtx1-1 & -18752.408 & 93.82 & 97.76 & $\begin{array}{l}\text { Favoured } \\
\text { regions:93.4 }\end{array}$ \\
initial & & & &
\end{tabular}

initial

Allowed regions: 6.6

Vtx1-1

$-18555.111 \quad 87.97$

91.59

Outlier regions: 0.0

refined

regions: 93.3

Vtx2 initial $15378.495 \quad 94.95$

$\begin{array}{llll}15378.495 & 94.95 & 87.28 & \text { Favoured }\end{array}$

Allowed regions: 6.7

Outlier regions: 0.4

regions: 87.6

Allowed regions: 11.7

Outlier regions: 0.8

Vtx2

$17386.025 \quad 80.00$

82.75

Favoured

regions: 85.8

Allowed regions: 13.5

Outlier regions: 0.7

Furthermore, the energy level of Vtx1-1 and Vtx2 was $-18555.111 \mathrm{~kJ} / \mathrm{mol}$ and $17386.025 \mathrm{~kJ} / \mathrm{mol}$, respectively after refinement. Native protein frequently folds into conformation with the lowest energy, which is the most constant form (Kazlauskas, 2018). These indicate that refined Vtx models via MODELLER (built-in Chimera 1.14) are closer and more related to the native models (Table 4).

Vtx1-1 and Vtx2 protein were modelled with the best match selections from the PDB structure database. In this study, Vtx1-1 was modelled in accordance with $4 \mathrm{~m} 1 \mathrm{u} \_$A while Vtx2 with $4 \mathrm{p} 2 \mathrm{c}$ A. Alignment of the new modelled structure of Vtx1-1 with $57.07 \%$ identity (Figure 2 (a)) while Vtx2 with $89.47 \%$ identity (Figure 2 (b)).

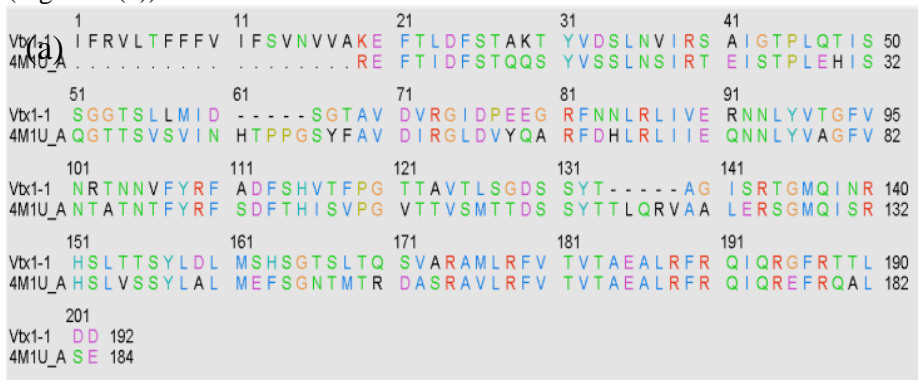

(b) 


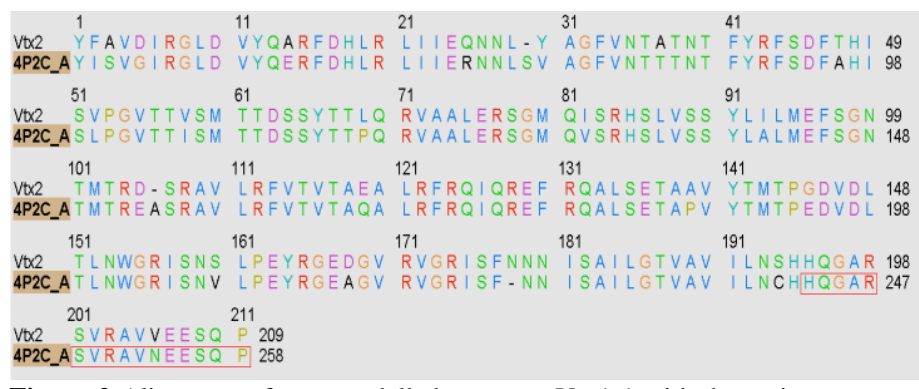

Figure 2 Alignment of new modelled structure Vtx1-1 with the native structure 4M1U_A (a) and (b) new modelled structure Vtx2 with native structure 4P2C

Alignment of both Vtx1-1 and Vtx2 was assessed by Needleman-Wunsch using BLOSUM-62 (Figure 3). Evaluation superpositions across in the final alignment overall RMSD: 0.797 and Q-score: 0.924 at cutoff 5.0 while 279 residues pairs were aligned. This alignment defines the secondary structure of proteins with the $86.87 \%$ identity.

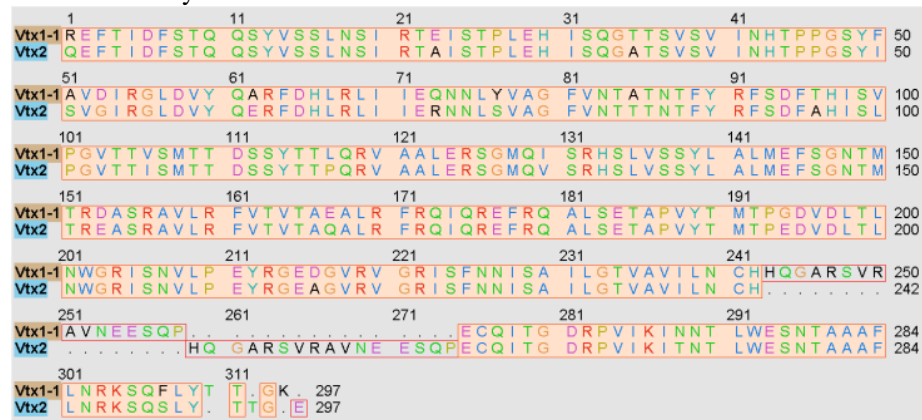

Figure 3 Alignment of the superimposed new structured model Vtx1-1 and Vtx2 Secondary structure prediction

All the modelled plasmid-mediated verotoxin gene of MN696158 (Vtx1-1) and MN688720 (Vtx2) contain 10 alpha-helices (H1-H10) and six $\beta$-strands (E1-E10) as shown in Fig 4. Despite the variations in amino acid residues in each VTX sequences (MN696158 and MN688720), the formation of secondary structures revealed a consensus between each verotoxin models (Vtx1-1 and Vtx2). This is because the protein structure is well preserved compared to the amino acid sequence throughout evolution (Dong et al., 2018). In addition, there is a preference for the collection of amino acid residues within a secondary structure (Figure 5). It can be shown that the residues of amino acids T, I, V, E and F are extremely abundant in the alpha-helix regions. These residues are classified as Helix Formats due to their low energy cost for helix formation. In the other hand, the residues of amino acids $\mathrm{Q}, \mathrm{S}, \mathrm{R}, \mathrm{T}, \mathrm{L}, \mathrm{V}, \mathrm{A}$ and $\mathrm{Y}$ are prevalent in beta strands due to the ability of their hydrophobic side chains to stabilize the $\beta$ structure (Merkel et al., 1999).

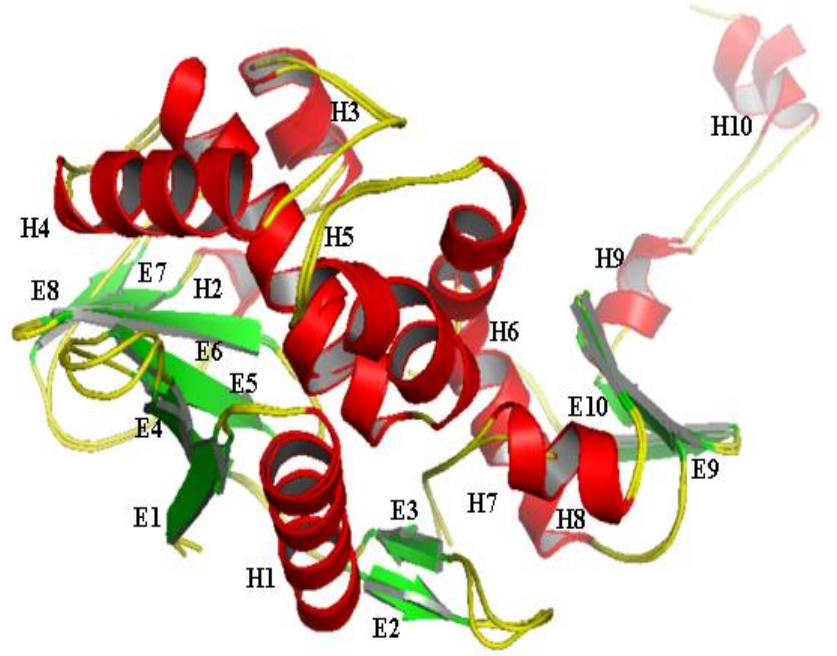

Figure 4 3D structure superimposition of Vtx1-1 and Vtx2. The $\alpha$-helices (H1H10), $\beta$-strands (E1-E10) and loops of Vtx are coloured in red, green, and yellow respectively
Legend of secondary structure icons:

$\begin{array}{lll}\text { H Alpha-Helix } & =\mathrm{T} & \text { Tum } \\ =\text { E Extended Configuration (Beta-sheet) } & =\mathrm{C} \text { or " " Coil } \\ \text { B Isolated Beta Bridge } & \mathrm{G} & 3 \cdot 10 \text { Helix } \\ ح \text { b Isolated Beta Bridge (Type 3 Fig 4,cd) } & \text { I I } & \text { Pi-Helix }\end{array}$

\section{Vtx1-1}

I REFTIDFSTQQSYVSSLSSIRTETSTPLEHISQOTTSVSVINHTPPOSTF50 31 AVDIROLDVYQARFDULRLITEQSNLYVAGFVSTATSTFYRFSDFTUISV100 101 POVTTVSMTTDSSYTTLQRVAALERSOMQTSRHSLVSSYLALMEFSONTMISO 15ITRDASRAVLRFVTVTAEALRFRQTQREFRQALSETAPVYTMTPODVDLTL200 201SWGRISNVLPEYRGEDGVRVORTSFNSISAILGTVAVILNCHECQITGDR2S0 251 PVIKINXTLWES XTAAAFLXRKSQFLYTTOK

\section{Vtx2}

1 QEFTIDFSTQQSYVSSLNSIRTATSTPLEHISQOATSVSVINHTPPGSY150 SI SVGIRGLDVYQERFDHLRLIIERNNLSVAGFVNTTTNTFYRFSDFAHISL100 101 PQVTTISMTTDSSYTTPQRVAALERSGMQVSRHSLVSSYLALMEFSGNTM150 ISITREASRAVLRFVTVTAQALRFRQTQREFRQALSETAPVYTMTPEDVDLTL.200 MINWORISNVLPEYRGEAOVRVGRTSFN ISAILOTVAVILNCHECQITGDR 200 251 PVIKITNTLWESNTAAAFLNRKSQSLYTTG

280

Figure 5 The legend of secondary structure (Vtx1-1 and Vtx2)

\section{Root-mean-square-deviation}

In this current analysis, RMSD values reflect VTEC's different thermal motion at the temperature concerned. Vtx1-11 The molecular dynamics simulation review (Figure 6 (a)) showed that Vtx1-1 retained an RMSD value of $3 \AA$ to 5 ns at 303 $\mathrm{K}$ and fluctuated from $1.5 \AA$ to $2.5 \AA$ to $30 \mathrm{~ns}$ and remained constant at $2 \AA$ until the end of the simulation. The RMSD value of Vtx1-1 at $313 \mathrm{~K}$ reached a plateau state at $2 \AA$ at $20 \mathrm{~ns}$ and maintained a constant deviation between $2.5 \mathrm{~A}$ and $3 \AA$ for the last $80 \mathrm{~ns}$ of the simulation. Vtx1-RMSD 1's value has steadily deviated from $1 \AA \sim 2 \AA$ to $65 \mathrm{~ns}$ at $323 \mathrm{~K}$. Slightly inclined to $3 \AA$ at $65 \mathrm{~ns}$ and minor variations between $1 \AA$ and $2 \AA$ during the simulation were also observed. At 303 $\mathrm{K}$, on the other hand, the RMSD value of Vtx2 (Figure 6 (b)) fluctuated marginally between $1 . \AA-2.5 \AA$ to $25 \mathrm{~ns}$ and held at $1.5 \AA$ until $100 \mathrm{~ns}$ of simulation continuously deviated. While Vtx2 showed a fluctuation between $1 \AA$ $3.5 \AA$ and 1 . at $313 \mathrm{~K}$, to $25 \mathrm{~ns}$ and steadily deviated to $\sim 2 \AA$ for the rest of the simulation process.
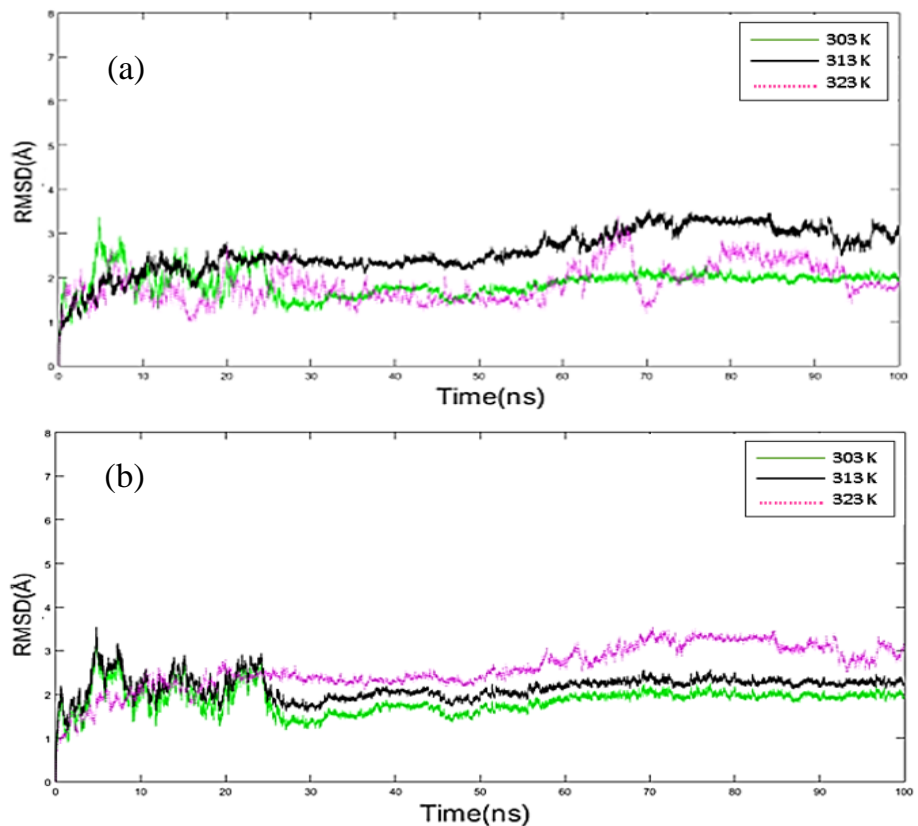

Figure 6 Root-mean-square deviation (RMSD) of the protein backbone as a time function at $303 \mathrm{~K}, 313 \mathrm{~K}$ and $323 \mathrm{~K}$ of (a)Vtx1-1 and (b) Vtx2

Furthermore, after $5 \mathrm{~ns}$, the RMSD value of Vtx2 entered a plateau state and continuously deviated from $2.5 \AA-3 \AA$ until $100 \mathrm{~ns}$ of simulation at $323 \mathrm{~K}$ During MD simulation, RMSD modifications suggest that the protein backbone of all VTEC structures has moved to a new conformation to preserve stability and versatility at different temperatures (Fields et al., 2015). The overall changes in RMSD (1.5-2.0 $\AA$ ) are considered minimal because the Vtx protein 
conformations (with the exception of Vtx2 at $323 \mathrm{~K}$ ) are depicted closely in line with their initial structures (Kato et al., 2017). The RMSD outcome therefore shows that the temperature has the least effect on Vtx1-1 and Vtx2, respectively. In addition, no significant deviation was observed at the time of the MD simulation of $100 \mathrm{~ns}$ after the RMSD plateau was reached by VTEC to allow VTEC to obtain a new constant conformation.

\section{Radius of gyrations}

Protein compactness is another way to calculate a protein's stability (Paul et al., 2014). From a Rg study, the impact of temperature on the VTEC dimension was assembled. At all temperatures, Vtx1-1 displayed a similar dimension of $\sim 19$ $\AA \sim 20 \AA$ Meanwhile, the $\mathrm{Rg}$ value of Vtx1-1 was stretched between $\sim 20 \AA$ until $100 \mathrm{~ns}$ at $303 \mathrm{~K}$, which corresponds to its RMSD changes that occurred at the same time frame. The $\mathrm{Rg}$ value was also held at $313 \mathrm{~K}$ and $323 \mathrm{~K}$ respectively at a steady value of 19.5-20.6 $\AA$ ((Figure 7 (a)). At all temperatures, the Rg value of Vtx2 has decreased to $19.5 \AA$ from $21.5 \AA$ between $20-100$ ns (Figure 7 (b)) Overall, during the simulation, the $\mathrm{Rg}$ of VTEC models remained stable indicating that VTEC structures are successful in preserving their original compactness even when the temperature rises.

Consequently, during the MD simulation study, the entire size of Vtx1-1 remained constant, although exceptions were observed on Vtx2. The shifts in $\mathrm{Rg}$ suggest that temperature plays a crucial role in the loosening of the protein system's molecular structural network and/or collapse at $323 \mathrm{~K}$ (Gu et al., 2019). The VTEC compactness analysis via Rg, similar to the RMSD analysis, also indicates that the Vtx1-1 model presents maximum stability at higher temperatures than $\mathrm{Vtx} 2$.
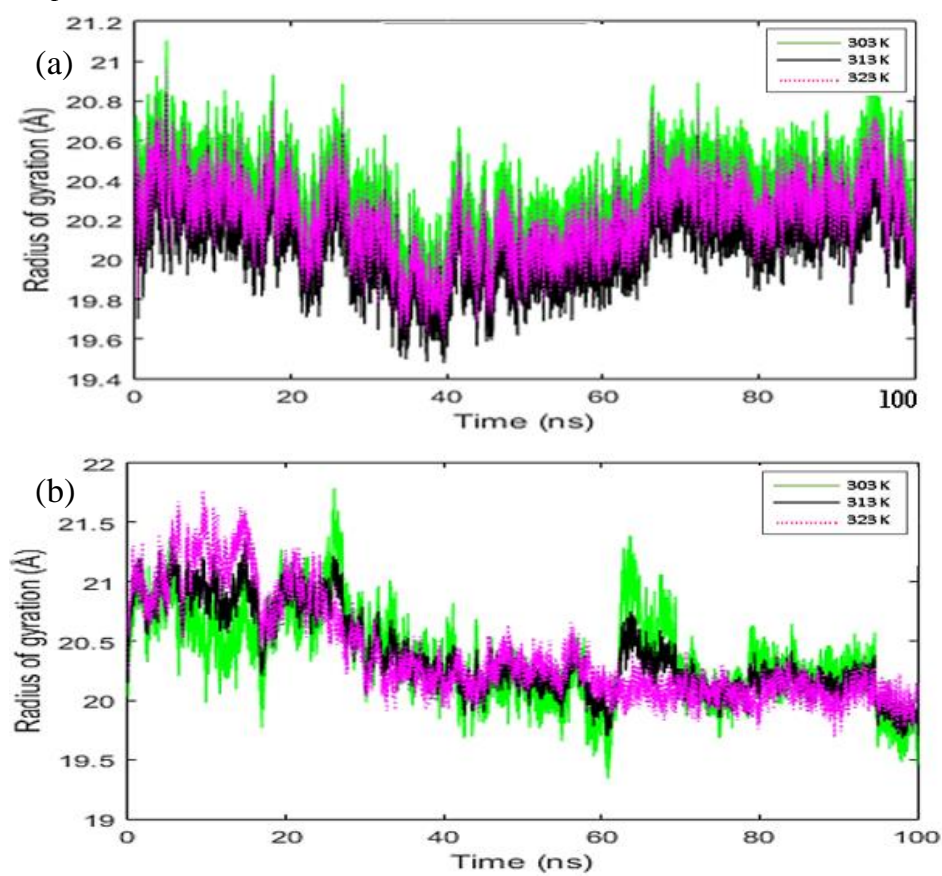

Figure 7 Radius of the gyration as a time function at $303 \mathrm{~K}, 313 \mathrm{~K}$ and $323 \mathrm{~K}$ of (a)Vtx1-1 and (b) Vtx2

A recent study shows that the hydrophobic effect and temperature play a major role in protein folding (Pucci \& Rooman, 2017). Hydrophilic residues are often present under normal conditions on the protein surface, while hydrophobic residues are often suppressed away from the aqueous environment within the protein (Ramli et al., 2018). The hydrophobic region is exposed to the solvent during the protein denaturation process (the enzyme loses its catalytic activity) (Paul et al., 2014). Soluble proteins, in interaction with the solvent, minimise the surface (Malleshappa et al., 2014)

\section{Solvent accessible surface area}

The hydrophobic effect is driven by protein folding of the solvent accessible surface area and is temperature dependent (Pucci \& Rooman, 2017). Under normal conditions, hydrophilic residues are usually located on the protein surface, while hydrophobic residues are generally buried within the protein away from the aqueous environment (Ramli et al., 2018). The solvent would be exposed to the hydrophobic region (Paul et al., 2014) if protein denaturation were to occur. Changes in SASA investigated the influence of temperature on the distribution of hydrophilic and hydrophobic residues of VTX models. In Vtx1SASA's value ranged from $\sim 106.10-114.81 \mathrm{~nm} 2$ at $303 \mathrm{~K}, \sim 107.05-113.10 \mathrm{~nm} 2$ at $313 \mathrm{~K}$ and $\sim 102.23-112.18 \mathrm{~nm} 2$ at $323 \mathrm{~K}$ (Figure 8 (a)). Meanwhile, the Vtx2 SASA retained at $303 \mathrm{~K}$ between $\sim 117.03-125.10 \mathrm{~nm} 2$, at $313 \mathrm{~K}$ between $\sim 113.63-126.02 \mathrm{~nm} 2$. Vtx2 maintained a stable SASA at 323K between $\sim 115.60$ $125.31 \mathrm{~nm} 2$ and maintained an average range of $108.12 \mathrm{~nm} 2$ until the simulation was completed (Figure 8 (b)).
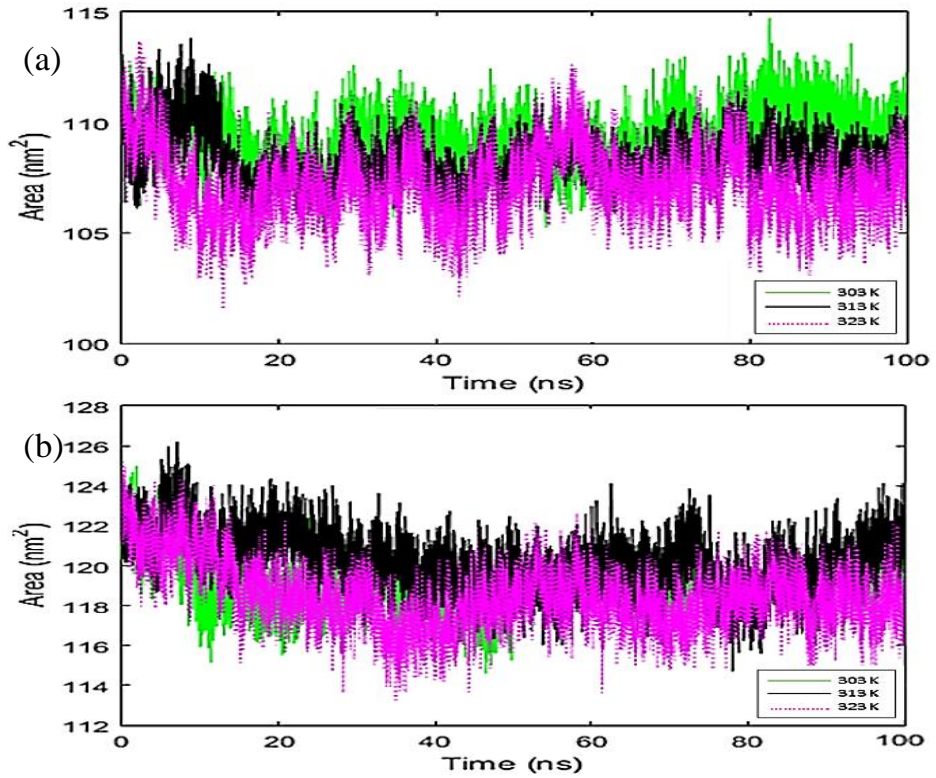

Figure 8 Solvent accessible surface area (SASA) of (a) Vtx1-1 and (b) Vtx2 as a time function at $303 \mathrm{~K}, 313 \mathrm{~K}$ and $323 \mathrm{~K}$

The SASA study of VTEC models showed a pattern close to that presented during the simulation phase by RMSD and Rg. The SASA study of Vtx1-1 and Vtx 2 showed stability at $303 \mathrm{~K}$ and $313 \mathrm{~K}$ respectively (native fold withou disruption). The SASA study of Vtx1-1 and Vtx2 was, by comparison, expanded, killed or unfolded at $323 \mathrm{~K}$. This enlargement of $\mathrm{Rg}$ showed that within the hydrophobic heart, hydrophobic molecules were distributed on the surface instead of suppressed. Furthermore, the decrease in SASA analysis is associated with the overall decrease in scale, resulting in high-temperature accumulation (Rosa et al., 2017). Residues congregate within the solvent protein, resulting in a decrease in SASA during protein aggregation (Mishra et al., 2018).

\section{Intramolecular hydrogen bonds}

The stability of the preservation of the protein structure is based on temperaturedependent interactions of the hydrogen bond (Pace et al., 2014). The hydrophobic effects, on the other hand, are the folding of the overall protein structure, since the hydrogen bond is directly connected to the protein structure (secondary and tertiary structure) and protein interaction selectivity (Gao et al., 2015). The Vtx11 and Vtx2 starting structures have intramolecular hydrogen bonds of 298 and 236, respectively (Figure 9). In comparison, the lowest number of intramolecular hydrogen bonds found in the Vtx2 models refers to distortion at high temperatures in RMSD, $\mathrm{Rg}$ and SASA.

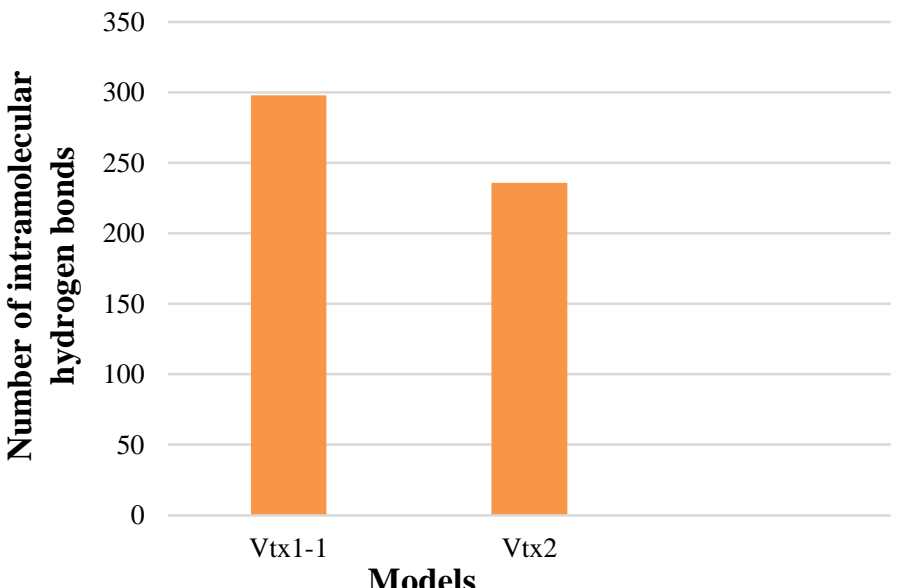

Figure 9 Number of intramolecular hydrogen bonds in the initial structure of Vtx1-1 and Vtx2

The simulation regardless of temperature plays an essential role in intramolecular hydrogen bonds. At $303 \mathrm{~K}, \mathrm{Vtx} 1-1$ retained an average number of 120.97 intramolecular hydrogen bonds (Figure 10 (a)). This average number further decreased to 113.94 at $313 \mathrm{~K}$ and increased to 124.26 at $323 \mathrm{~K}$ respectively. In addition, Vtx 2 has an average number of 137.37 intramolecular hydrogen bonds at $303 \mathrm{~K}, 138.30$ at $313 \mathrm{~K}$ and 142.30 at $323 \mathrm{~K}$, respectively (Figure 10 (b)). 

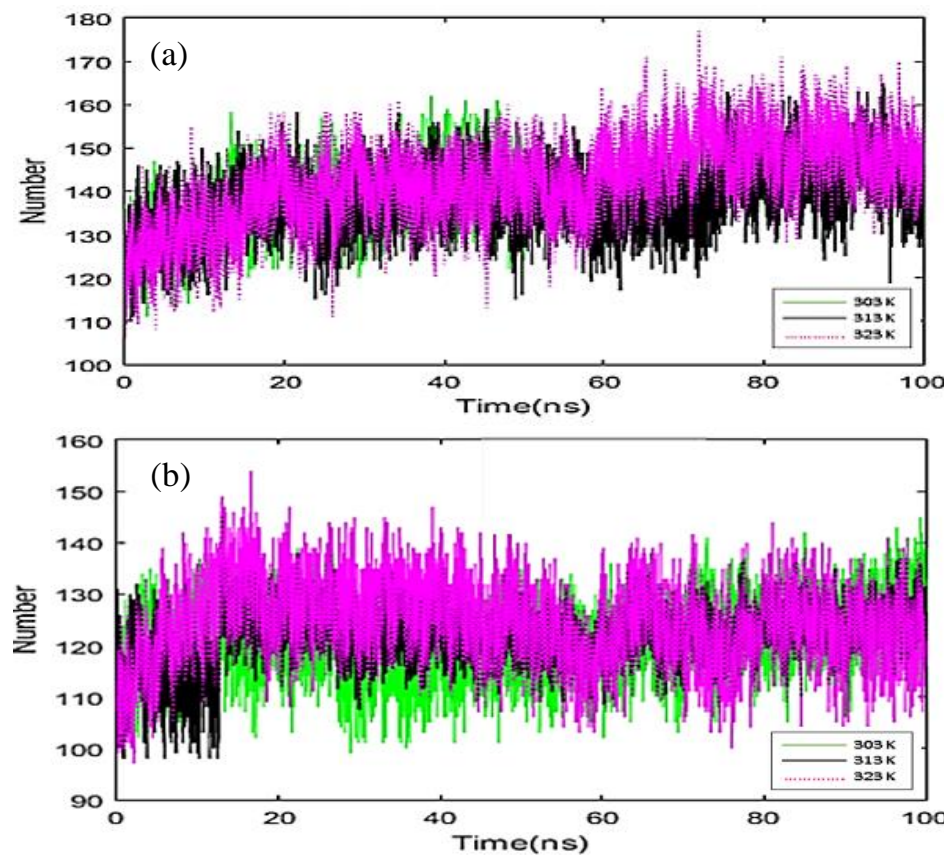

Figure 10 Number of hydrogen intramolecular bonds of (a) Vtx1-1 and (b) Vtx2 as a function of time at $303 \mathrm{~K}, 313 \mathrm{~K}$ and $323 \mathrm{~K}$

This result specifies the hydrogen bond network within the Vtx structures. Besides, the Vtx structure stability was disrupted and weakens as the temperature rises in accordance with a recent study (Mallamace $\boldsymbol{e t}$ al., 2018).

\section{Root-mean-square fluctuation}

At residue level, the stability of verotoxin (VTX) was also experienced. The flexibility and mobility of protein residues at various temperatures has been demonstrated by RMSF. In Vtx1-1, the fluctuation was recorded at residue position of 4-8, 45-48, 121-124, and 190-192 at 303 K (Figure 11 (a)). These residues also fluctuated at $4-12,43-52$ at $313 \mathrm{~K}$ and $44-51$ at $323 \mathrm{~K}$, respectively. In the meantime, Vtx2 demonstrated versatility at different residue positions $198-207$ at $303 \mathrm{~K}, 5-12,21-26,40-47,197-199,313 \mathrm{~K}$ at $200-205$ and $323 \mathrm{~K}$ at 9-11, 157-160, 161-165, 204-208 (Figure 11 (b)).
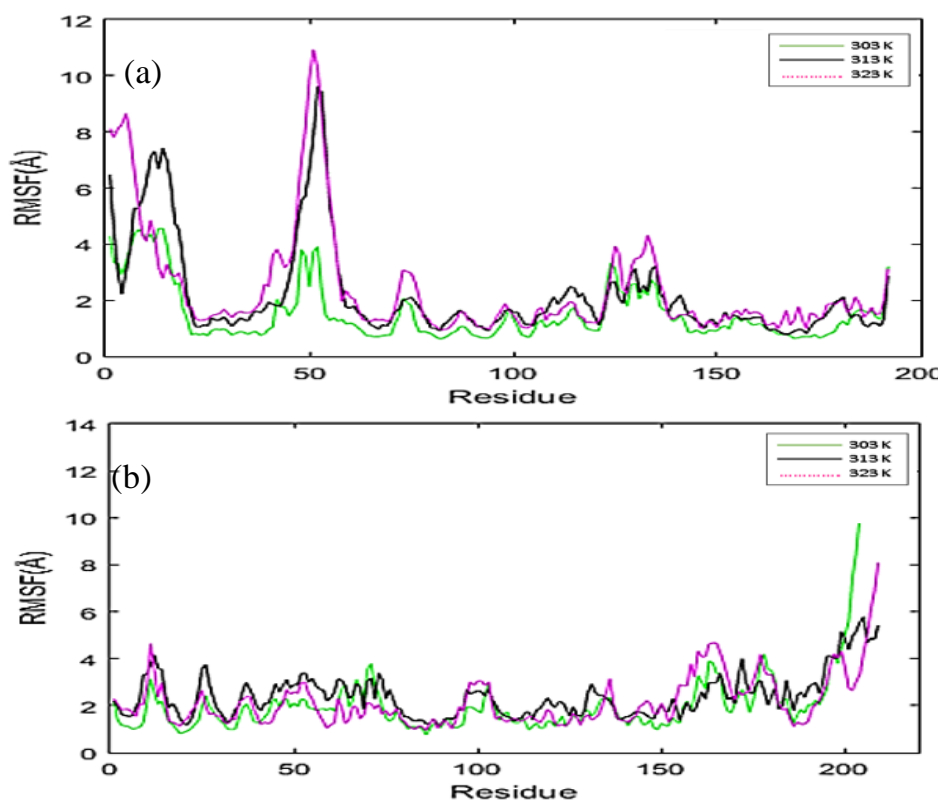

Figure 11 RMSF of (a) Vtx1-1 and (b) Vtx2 residues number at $303 \mathrm{~K}, 313 \mathrm{~K}$ and $323 \mathrm{~K}$.

After the first 100 protein residues in the Vtx 2 model, residue variations were more prominent. At the same time, the residues for the remaining position were relatively less fluctuating. Higher RMSF values suggest greater flexibility in conformation and may become unstable as the temperature increases (Du et al., 2017).

The physicochemical properties of the residues of amino acids affect protein stability and versatility (Alvarez-Ponce et al., 2018). From the thermal sensitive regions, the effect of amino acid composition on Vtx1-1 sequence information was obtained. TIDFSTQQS, HTPPGSYFAV, AALE, TMT, IDFSTQQS
RTAIST, VINHTPPG, AVLRFVTVT, and DLTLNWGRISNV are the temperature-sensitive sequences listed (Table 5). Fluctuations in the MD simulation study is responsible for the most common amino acid residues: asparagine, aspartic acid, cysteine, lysine, glutamine, glycine, serine, threonine and tyrosine. Asparagine, cysteine, glutamine, glycine, serine, threonine and tyrosine are non-charged among the amino acid residues known and are unable to define sufficient hydrogen bonds to stabilise structures (Ramli et al., 2012).

\begin{tabular}{lll}
\multicolumn{2}{l}{ Table 5 Sequence ranges on the fluctuated zones } & \\
\hline Model & Fluctuated region & Sequence \\
\hline Vtx1-1 & $4-12$ & TIDFSTQQS \\
& $43-52$ & HTPPGSYFAV \\
& $121-124$ & AALE \\
& $190-192$ & TMT \\
Vtx2 & $5-12$ & IDFSTQQS \\
& $21-26$ & RTAIST \\
& $40-47$ & VINHTPPG \\
& $157-165$ & AVLRFVTVT \\
& $197-208$ & DLTLNWGRISNV \\
\hline
\end{tabular}

In summary, MN696158 (Vtx1-1) and MN688720 (Vtx2) showed key differences in their respective versatility of conformation and stability of temperature rise. MN696158 (Vtx1-1) is the most thermostable VTX model exhibited during the simulation process due to its least deviated dynamics. In the meantime, RMSD shows that as temperature rises, MN688720 (Vtx2) is the least stable model of plasmid-mediated VTX models. On the other hand, in Rg, SASA and differences between intramolecular and intermolecular hydrogen bonds, Vtx2 showed denature activity. In contrast, RMSF analysis exhibited that the initial fluctuated regions are protein loops located in the L-subdomain with a temperature increase due to lack of hydrophobicity and electrostatic interfaces. The results of the current study provide a deeper understanding of protein structural analysis in an essential region of molecular synthesis and will greatly improve successful and focused intervention approaches.

\section{CONCLUSION}

In this study, we reported structural analysis of two plasmid-mediated verotoxin gene sequences. Despite these plasmid-mediated verotoxin gene sequences showed slight differences in sequence level. The 3D verotoxin models produced demonstrated remarkable variations in their relative versatility of compliance and stability when the temperature increased. Protein loops on the L-subdomain are among the key fluctuated temperature-increasing regions because of the lack of electrostatic interactions and hydrophobicity in this region. It is predicted that a thermal, stable plasmid mediated verotoxin gene model can be best suitable model for the predictions of vaccine developments through the protein engineering process of structural information obtained.

\section{Conflict of study: None}

Acknowledgement: We are grateful to Universiti Malaysia Pahang and Hospital Tengku Ampuan Afzan, Malaysia for research facilities. We also thank Medica Research \& Ethics Committee (MREC), Malaysia for ethical approval. Author [Md. Fazlul Karim Khan] is thankful to Universiti Malaysia Pahang for providing Doctoral Research Scholarship (DRS) and Postgraduate Research Grants Scheme (PGRS 180360) as a financial support.

\section{REFERENCES}

Amir, A., Kapoor, N., Kumar, H., Tariq, M., \& Siddiqui, M. A. (2019). In silico homology modeling and epitope prediction of drug target protein in human herpes virus 8 (HHV8). Biotech Today: An International Journal of Biological Sciences, 9(1), 41-48.http://dx.doi.org/10.5958/2322-0996.2019.00005.X

Chakkyarath, V., \& Natarajan, J. (2019). Identification of Ideal Multi-targeting Bioactive Compounds Against Mur Ligases of Enterobacter aerogenes and Its Binding Mechanism in Comparison with Chemical Inhibitors. Interdisciplinary Sciences: Computational Life Sciences, 11(1), 135144.http://dx.doi.org/10.1007/s12539-017-0261-4

Chakravarty, S., Godbole, S., Zhang, B., Berger, S., \& Sanchez, R. (2008) Systematic analysis of the effect of multiple templates on the accuracy of comparative models of protein structure. BMC structural biology, 8(1), 31

Cheung, V., \& Trachtman, H. (2014). Hemolytic uremic syndrome: toxins, vessels, and inflammation. Front Med (Lausanne) 1 42.http://dx.doi.org/10.3389/fmed.2014.00042

Cloete, R., Kapp, E., Joubert, J., Christoffels, A., \& Malan, S. F. (2018) Molecular modelling and simulation studies of the Mycobacterium tuberculosis multidrug efflux pump protein Rv1258c. PloS One, 13(11) e0207605.http://dx.doi.org/10.1371/journal.pone.0207605

Colello, R., Caceres, M. E., Ruiz, M. J., Sanz, M., Etcheverria, A. I., \& Padola, N. L. (2016). From farm to table: follow-up of Shiga toxin-producing 
Escherichia coli throughout the pork production Chain in Argentina. Frontiers in Microbiology, 7, 93.http://dx.doi.org/10.3389/fmicb.2016.00093

Dong, R., Pan, S., Peng, Z., Zhang, Y., \& Yang, J. (2018). mTM-align: a server for fast protein structure database search and multiple protein structure alignment. Nucleic acids research, 46(W1), W380-W386

Dorn, M., e Silva, M. B., Buriol, L. S., \& Lamb, L. C. (2014). Three-dimensiona protein structure prediction: Methods and computational strategies. Computational Biology and Chemistry, 53, 251276.http://dx.doi.org/10.1016/j.compbiolchem.2014.10.001

Duanis-Assaf, D., Kenan, E., Sionov, R., Steinberg, D., \& Shemesh, M. (2020). Proteolytic Activity of Bacillus subtilis upon $\kappa$-Casein Undermines Its "CariesSafe" Effect. Microorganisms, 8(2), 221

Elengoe, A., Naser, M. A., \& Hamdan, S. (2014). Modeling and docking studies on novel mutants (K71L and T204V) of the ATPase domain of human heat shock $70 \mathrm{kDa}$ protein 1. International Journal of Molecular Sciences, 15(4), 6797 6814.http://dx.doi.org/10.3390/ijms15046797

Faure, G., Joseph, A. P., Craveur, P., Narwani, T. J., Srinivasan, N., Gelly, J. C., Rebehmed, J., \& de Brevern, A. G. (2019). iPBAvizu: a PyMOL plugin for an efficient 3D protein structure superimposition approach. Source Code for Biology and Medicine, 14(1), 5.http://dx.doi.org/10.1186/s13029-019-0075-3

Fazlul, M., Rashid, S. S., Nazmul, M., Zaidul, I., Baharudin, R., \& Nor, A. (2018). A clinical update on antibiotic resistance gram-negative bacteria in Malaysia-A review. Journal of International Pharmaceutical Research, 45, 270 283

Fazlul, M., Zaini, M., Rashid, M., \& Nazmul, M. (2011). Antibiotic susceptibility profiles of clinical isolates of Pseudomonas aeruginosa from Selayang Hospital, Malaysia. Biomedical Research, 22(3), 263 266. https://doi.org/10.1016/j.ijid.2012.05.589

Feig, M. (2017). Computational protein structure refinement: Almost there, yet still so far to go. Wiley Interdisciplinary Reviews: Computational Molecular Science, 7(3), e1307.http://dx.doi.org/ARTN E1307 10.1002/wcms.1307

Frith, M. C. (2019). How sequence alignment scores correspond to probability models.

Bioinformatics,

$36(2)$

408

415.http://dx.doi.org/10.1093/bioinformatics/btz576

Ganugapati, J., \& Akash, S. (2017). Multi-template homology based structure prediction and molecular docking studies of protein 'L'of Zaire ebolavirus (EBOV). Informatics in Medicine Unlocked, 9, 68-75

Geng, H., Chen, F., Ye, J., \& Jiang, F. (2019). Applications of molecular dynamics simulation in structure prediction of peptides and proteins Computational and Structural Biotechnology Journal, 17, 1162 1170.http://dx.doi.org/10.1016/j.csbj.2019.07.010

Haddad, Y., Adam, V., \& Heger, Z. (2020). Ten quick tips for homology modeling of high-resolution protein 3D structures. PLoS Computational Biology, 16(4), e1007449.http://dx.doi.org/10.1371/journal.pcbi.1007449

Hai-You, D., Ya, J., \& Yang, Z. (2016). Protein structure prediction. Acta Physica Sinica, 65(17)

Hazards, E. P. (2013). Scientific opinion on VTEC-seropathotype and scientific criteria regarding pathogenicity assessment. EFSA Journal, 11(4), 3138

Heo, L., \& Feig, M. (2018). Experimental accuracy in protein structure refinement via molecular dynamics simulations. Proceedings of the National Academy of $\quad$ Sciences, $115(52), \quad 13276$ 13281.http://dx.doi.org/10.1073/pnas.1811364115

Huang, J., Rauscher, S., Nawrocki, G., Ran, T., Feig, M., de Groot, B. L., Grubmüller, H., \& MacKerell, A. D. (2017). CHARMM36m: an improved force field for folded and intrinsically disordered proteins. Nature methods, 14(1), 71 73

Jing, X., \& Dong, Q. (2017). MQAPRank: improved global protein model quality assessment by learning-to-rank. BMC Bioinformatics, 18(1), 275.http://dx.doi.org/10.1186/s12859-017-1691-z

Kaper, J. B., \& O'Brien, A. D. (2014). Overview and historical perspectives Microbiology Spectrum, 2(6).http://dx.doi.org/10.1128/microbiolspec.EHEC0028-2014

Kazlauskas, R. (2018). Engineering more stable proteins. Chemical Society Reviews, 47(24), 9026-9045.http://dx.doi.org/10.1039/C8CS00014J

Kerfeld, C. A., \& Scott, K. M. (2011). Using BLAST to teach "E-value-tionary" $\begin{array}{llll}\text { concepts. } & P L O S & \text { Biology, } & \text { 9(2), }\end{array}$ e1001014.http://dx.doi.org/10.1371/journal.pbio.1001014

Khan, M. F. K., Kabir, M. N., Rashid, S. S., Tayan, O., \& Maziz, M. N. H. (2020). Computational Investigation on Protein Sequence of Non-O157 VTEC for Potentiality of Vaccine Production. Paper presented at the 2020 IEEE International Conference on Automatic Control and Intelligent Systems (I2CACIS).

Khan, M. F. K., Rashid, S. S., Maziz, M. N. H., Ramli, A. N. M., \& Baharuddin, R. (2020). Plasmid-mediated verotoxin producing non-O157 Escherichia coli isolates from Malaysia. International Journal of Infectious Diseases, 101, 138.http://dx.doi.org/10.1016/j.ijid.2020.09.374

Khan, M. F. K., Rashid, S. S., Ramli, A. N. M., Maziz, M. N. H., \& Roesnita, B (2020). Molecular Characterization of Plasmid-Mediated Non-O157 Verotoxigenic Escherichia coli Isolated from Infants and Children with Diarrhea.
Baghdad Science Journal,

$17(3)$,

0710

0710.http://dx.doi.org/10.21123/bsj.2020.17.3.0710

Lobanov, M. Y., Bogatyreva, N., \& Galzitskaya, O. (2008). Radius of gyration as an indicator of protein structure compactness. Molecular Biology, 42(4), 623 628.http://dx.doi.org/10.1134/S0026893308040195

Mallamace, D., Fazio, E., Mallamace, F., \& Corsaro, C. (2018). The role of hydrogen bonding in the folding/unfolding process of hydrated lysozyme: A review of recent NMR and FTIR results. International Journal of Molecular Sciences, 19(12), 3825.http://dx.doi.org/10.3390/ijms19123825

Mei, G. Y., Tang, J., Carey, C., Bach, S., \& Kostrzynska, M. (2015). The effect of oxidative stress on gene expression of Shiga toxin-producing Escherichia coli (STEC) O157:H7 and non-O157 serotypes. International Journal of Food Microbiology, 215, 7-15.http://dx.doi.org/10.1016/j.ijfoodmicro.2015.07.029

Merkel, J. S., Sturtevant, J. M., \& Regan, L. (1999). Sidechain interactions in parallel $\beta$ sheets: the energetics of cross-strand pairings. Structure, 7(11), 13331343

Monzon, A. M., Zea, D. J., Marino-Buslje, C., \& Parisi, G. (2017). Homology Modeling in a Dynamical World. Protein Science, 26(11), 2195 2206.http://dx.doi.org/10.1002/pro.3274

Muhammed, M. T., \& Aki-Yalcin, E. (2019). Homology modeling in drug discovery: Overview, current applications, and future perspectives. Chemical Biology \& Drug Design, 93(1), 12-20.http://dx.doi.org/10.1111/cbdd.13388

Nazmul, M., Fazlul, M., \& Rashid, M. (2012). Plasmid profile analysis of nonO157 diarrheagenic Escherichia coli in Malaysia. Indian Journal of Science, 1(2), 130-132

Paul, M., Hazra, M., Barman, A., \& Hazra, S. (2014). Comparative molecular dynamics simulation studies for determining factors contributing to the thermostability of chemotaxis protein "CheY". Journal of Biomolecular Structure and Dynamics, 32(6), 928-949

Public Health England. (2018). Epidemiology of Non-O157 Shiga toxin producing Escherichia coli (STEC). Retrieved from https://assets.publishing.service.gov.uk/government/uploads/system/uploads/attac hment data/file/732577/non-O157 STEC Evidence Base.pdf

Pucci, F., \& Rooman, M. (2017). Physical and molecular bases of protein therma stability and cold adaptation. Current Opinion in Structural Biology, 42, 117 128.http://dx.doi.org/10.1016/j.sbi.2016.12.007

Ramli, A. N. M., Manas, N. H. A., Hamid, A. A. A., Hamid, H. A., \& Illias, R. M. (2018). Comparative structural analysis of fruit and stem bromelain from Ananas comosus. Food Chemistry, 266, 183 191.http://dx.doi.org/10.1016/i.foodchem.2018.05.125

Raval, A., Piana, S., Eastwood, M. P., Dror, R. O., \& Shaw, D. E. (2012) Refinement of protein structure homology models via long, all-atom molecular dynamics simulations. Proteins: Structure, Function, and Bioinformatics, 80(8), 2071-2079.http://dx.doi.org/10.1002/prot.24098

Sajib, S. A., Billah, M., Mahmud, S., Miah, M., Hossain, F., Omar, F. B., Roy, N. C., Hoque, K. M. F., Talukder, M. R., \& Kabir, A. H. (2020). Plasma activated water: the next generation eco-friendly stimulant for enhancing plant seed germination, vigor and increased enzyme activity, a study on black gram (Vigna mungo L.). Plasma Chemistry and Plasma Processing, 40(1), 119 143.http://dx.doi.org/10.1007/s11090-019-10028-3

Sefidbakht, Y., Ranaei Siadat, O., \& Taheri, F. (2017). Homology modeling and molecular dynamics study on Schwanniomyces occidentalis alpha-amylase. Journal of Biomolecular Structure and Dynamics, 35(3), 574 584.http://dx.doi.org/10.1080/07391102.2016.1154892

Soumiya, S., Santhiagu, A., Manjusha, C., Adarsh, V., \& Prakash, S. J. (2019) Homology modeling and structural validation of gel $\mathrm{c}$ gene involved in the biosynthesis of gellan from sphingomonas paucimobilis ATCC 31461. Research Journal of Pharmacy and Technology, 12(3), 1044-1050

Su, X. D., Zhang, H., Terwilliger, T. C., Liljas, A., Xiao, J., \& Dong, Y. (2015) Protein crystallography from the perspective of technology developments. Crystallography Reviews, 21(1-2),

153.http://dx.doi.org/10.1080/0889311X.2014.973868

Tran, N. T., Jakovlić, I., \& Wang, W.-M. (2015). In silico characterisation, homology modelling and structure-based functional annotation of blunt snout bream (Megalobrama amblycephala) Hsp70 and Hsc70 proteins. Journal of Animal Science and Technology, 57(1), 44.http://dx.doi.org/10.1186/s40781-0150077-X

Webb, B., \& Sali, A. (2017). Protein structure modeling with MODELLER. In Functional Genomics (pp. 39-54): Springer.

Wei, D. Q., Ma, Y., Cho, W. C. S., Xu, Q., \& Zhou, F. (2017). Translational bioinformatics and its application: Springer Netherlands.

Zhu, F., Zhou, Y. K., Ji, Z. L., \& Chen, X. R. (2018). The Plant ribosomeinactivating proteins play important roles in defense against pathogens and insect pest attacks. Frontiers in Plant Science, 9 146.http://dx.doi.org/10.3389/fpls.2018.00146 